\title{
NATIONAL SEMINAR ON \\ ANTIMICROBIAL RESISTANCE - A GLOBAL MENACE: ONE HEALTH APPROACH
}

\section{PROCEEDINGS}

The Indian Journal of Animal Health (IJAH), a journal dedicated to promote the art of Veterinary and Animal Sciences with their relation to public health and agriculture since 1962 and the publication of the West Bengal Veterinary Association (WBVA), Kolkata, organized a one day National Seminar on "Antimicrobial Resistance (AMR) - A global menace: One health approach" on 07.03.2020 at Vivek Bhavan, West Bengal University of Animal and Fishery Sciences, Belgachia, Kolkata, West Bengal. The program started with the registration of participants from various sectors of biological sciences, students, research scholars and non-governmental organizations. The technical programme was initiated with the reception of the guests on the dais. The National Seminar was inaugurated by watering the plant sibling by all the guests. Prof. P. K. Das, Editor, IJAH welcomed the guests and narrated the activities of IJAH particularly on the recent interventions and directions on the Journal's publication and the future endeavours. Following the introductory address on the activities of WBVA by the General Secretary, Dr. Partha Sarkar, the special issue on 'Drug Resistance: Animal and Fish Production' brought out by IJAH as well as the book authored by Dr. I. Samanta and Dr. S. Bandopadhyay, and published by Elsivier were released by Dr. Basanta Kumar Das, the Chief Guest of the Seminar.

The National Seminar was started with the presentation of seminar base paper by Dr. I. Samanta. He enlightened the audience on the need of the seminar on AMR, the possible complicated issues arisen due to the transmission of antibioticresistant bacteria (ARB) into the human food chains from livestock and fish, the extra financial burden associated with the increased treatment cost as well as a prolonged hospital stay. He further

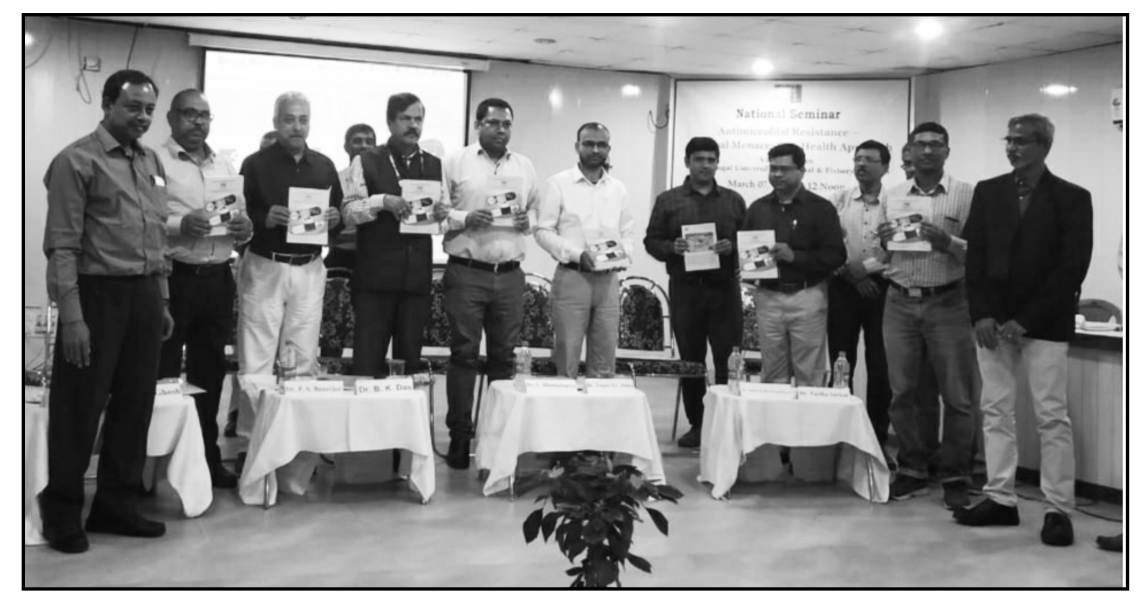

Inauguration of Special Issue of IJAH 


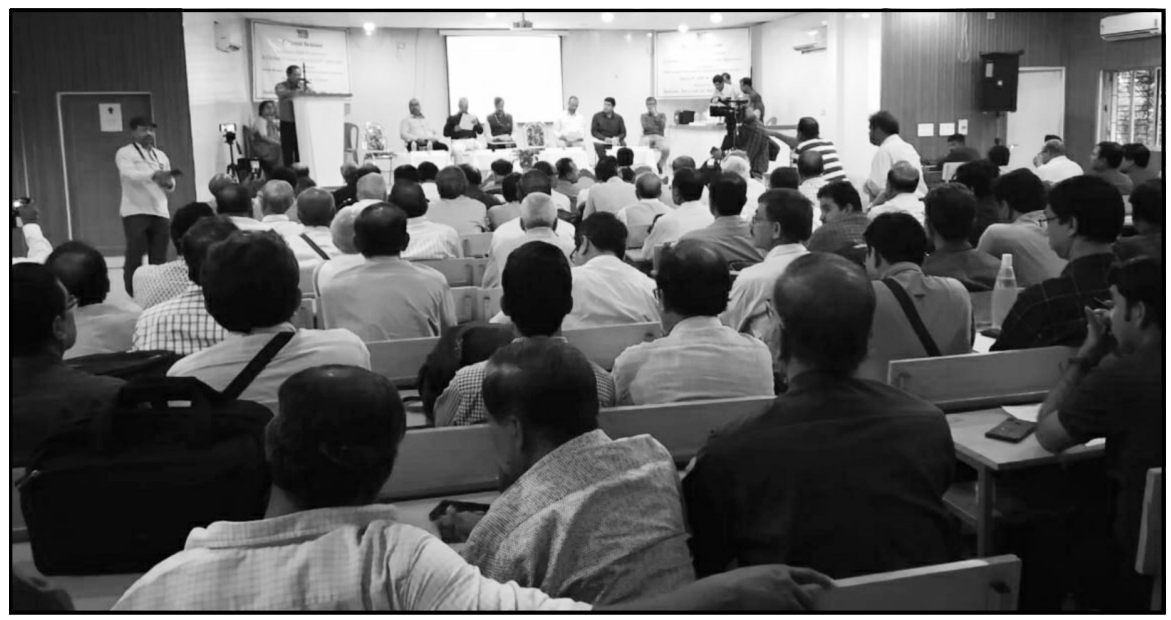

Part of audience on the seminar

stressed on the World Health Organization's projection on mortality due to ARB by 2050 and the need to work together under the same umbrella, one medicine; one world; One health approach.

The technical programme of the National Seminar was jointly conducted by Prof. T. J. Abraham as Chairman and Prof. S. N. Joardar as Cochairman. They were ably supported by the team comprising Dr. P. R. Ghosh, Dr. T. K. Sar, and Dr. A. K. Patra as Rapporteurs.

Dr. Basanta Kumar Das, Director, ICAR-Central Inland Fisheries Research Institute, Barrackpore and Fish Pathologist of International repute presented the keynote address on "Antimicrobial resistance (AMR): Differential drivers across the ecosystem". His speech highlighted the emergence of ARB in every niche of the environment. He emphasized that the aquatic environment is serving as a natural reservoir of antibiotic resistance and a conduit for the spread of clinical resistance traits, as pharmaceutical wastewater and hospital effluents are released into the nearby water bodies without adequate treatments. Also, he indicated that the majority of the aquatic bacteria are unculturable, a distinct characteristic from that of human and animal pathogens, and therefore, the full understanding of the factors driving the behaviour of antibioticresistant genes (ARGs) in the aquatic realm is difficult. Also, the use and abuse of antibiotics in aquaculture have become a serious global problem due to the development and diffusion of antibiotic resistance and accumulation of drug residues in edible tissues. He, therefore, urged the use of ecofriendly alternatives for prophylactic and therapeutic purposes in fish health management. He further urged a multidisciplinary approach involving researchers from medical, veterinary, aquaculture, environmental and extension sciences to control the spread of antibiotic resistance and promulgation of strict rules and regulations on the use of antibiotics in each and every health sectors. He suggested the next-generation sequencing and metagenomic approaches for the deeper understanding on the behaviour of ARGs in the aquatic environment and other niches, and to understand the origins of antibiotic resistance in order to slow their spread.

Dr. S. Bhattacharya, Consultant Microbiologist, Tata Memorial Center, New Town, Kolkata gave his deliberation on "AMR in human health: An Indian perspective". He raised the concern on the increasing uses of antibiotics in the livestock health sectors $(70 \%)$ in many developed and developing countries than in human health sectors $(30 \%)$, the transfer of ARGs from animals to human and more particularly on the emergence of colistin resistance, a drug of choice for the control of multidrug-resistant bacterial infections. He highlighted the importance of the study of the microbiome, factors affecting microbiome and the positive effects of introductions of new interventions to reduce the AMR. 


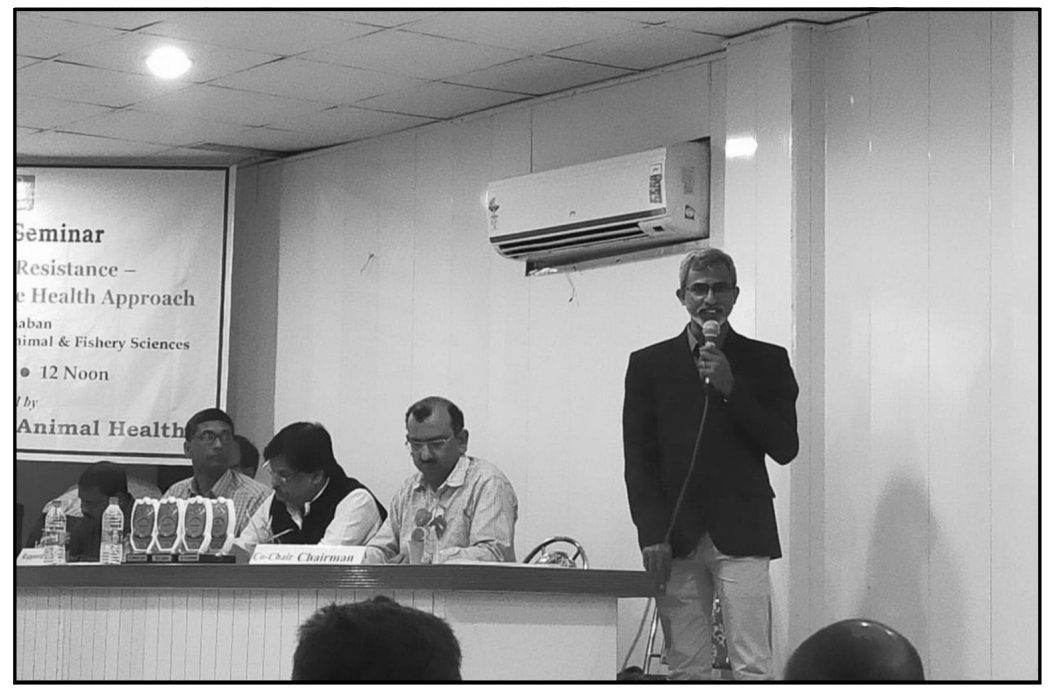

Chairman, Co-chairman and Rapportier conducting the session

Dr. Tapan Kumar Dutta, Professor and Head, Dept. of Veterinary Microbiology, Central Agricultural University, Aizawl, Mizoram spoke on the "Post-antibiotic era: Alternative approaches". His deliberations were focused on the possible solutions to combat AMR. He narrated the issues related to the development of new antibiotics and their commercialization and suggested the use of alternatives to antibiotics through (i) natural means such as phage therapy, antimicrobial peptides and bacteriocins, probiotics, faecal transplantation and predatory bacteria, and (ii) synthetic products such as synthetic mimics of antimicrobial peptides, innate defense regulatory peptides, antibacterial oligonucleotides, and inhibitors of bacterial virulence. He further highlighted the importance of biotechnological approaches to mitigate the AMR by means of genetically modified bacteriophages, lysins, and CRISPR-Cas-9.

Dr. Samiran Bandopadhyay, Senior Scientist, ICAR-Indian Veterinary Research Institute (ERS), Kolkata deliberated on the "Emergence of colistin resistance: An update". The highlights of his deliberations were the increasing incidence or emergence of colistin resistance in the livestock sectors, lack of organized surveillance on AMR, ban on the use of colistin as an animal feed additive in India, and the ICAR initiatives on "Indian Network for Fisheries and Animal Antimicrobial Resistance (INFAAR)".

Dr. P. S. Banerjee, Principal Scientist and Incharge of Eastern Regional Station (ERS), ICAR-Indian Veterinary Research Institute (ICAR-IVRI), Kolkata enlightened the audience on the use and abuse of antihelminthic drugs and the development of resistance to those drugs in the livestock health sectors. He advocated the importance of correct diagnosis prior to therapy.

Dr. M. Ghosh, Principal Scientist and In-charge of Eastern Regional Station (ERS), ICARNational Dairy Research Institute (ICAR-NDRI), Kalyani emphasized on the importance of proper animal nutrition in the livestock production for immunity diseases prevention and mitigating the development and spread of AMR.

Dr. Ashis Nandi, representative of Paschim Banga Vignan Mancha (PBVM), Kolkata shared his views on the AMR and the efforts taken by the PBVM on this emerging problem.

The deliberations of the National Seminar were summed up by the Chairman and the Cochairman of the technical session. 


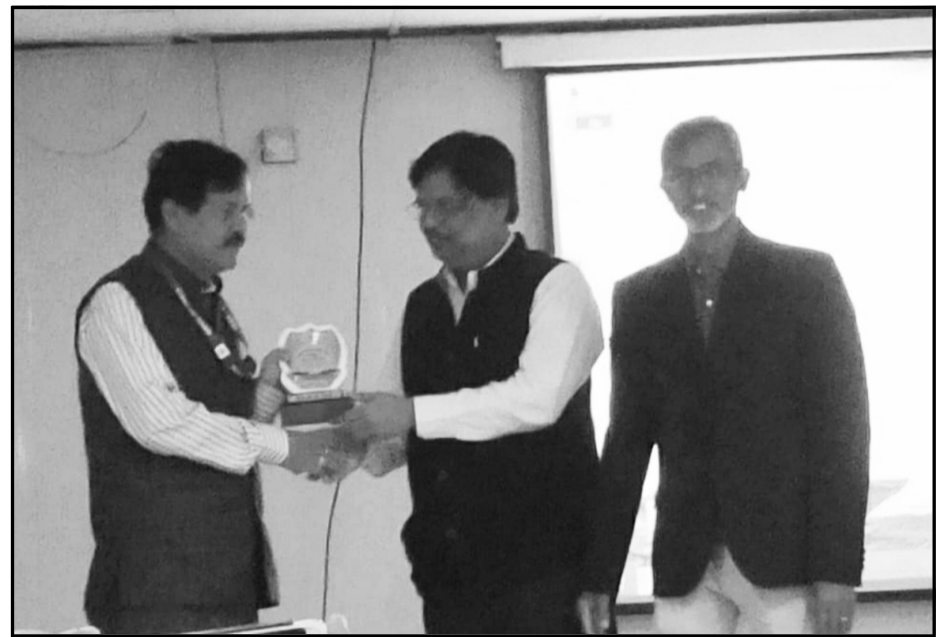

Reception to the inaugurator Dr. B. K. Das

The recommendations of the technical session on AMR were presented by Prof. Subhasish Biswas, Senior Editorial Board Member, IJAH, Kolkata.

Dr. Aloke Mukherjee, Chairman, Publication Board, IJAH proposed the vote of thanks.

\section{Recommendations of the Seminar}

1. Antimicrobial resistance is a multifactorial and complex issue which is associated with several core sectors such as human and animal health, fishery, agriculture and environment. To tackle the global menace, all the stakeholders need to work together under the same umbrella of 'One Medicine: One world: One health approach.

2. A national network programme is essential to understand the antimicrobial resistant bacteria circulating among humans, animals, birds and environment in the country and in this part of the country in particular.

3. Special emphasis must be set on the resultoriented proven suitable alternatives to antibiotics for therapeutic purposes of humans and animals. The discovery of new antibiotics with conservation of sensitivity of old antimicrobial drugs should be given utmost priority to address the global health menace of antimicrobial resistance.
4. Use of antimicrobials by human and animal practitioners must be judicious and supported with a proper guideline created and updated regularly by the apex bodies. In addition, all the state Governments must proclaim the antimicrobial use policy for stringent compliance on their applications by all the stakeholders.

5. A proper regulation is essentially required for immediate ban of in-feed antibiotic growth promoters including antiprotozoal drugs in animal, poultry and fish feeds.

6. The critical and overlapping antibiotics used in humans must be excluded for nontherapeutic uses in livestock and fishery sectors.

7. The national curriculum at school level should have a chapter or section on the responsible use of antibiotics.

8. Non-medical practitioners should be trained and monitored regarding this health issue.

9. Regular awareness campaigns for antimicrobial resistance are needed for the responsible uses of antimicrobials at all levels. 